\title{
Crash Performance of Oil Palm Empty Fruit Bunch (OPEFB) Fibre Reinforced Epoxy Composite Bumper Beam using Finite Element Analysis
}

\author{
C. S. Hassan ${ }^{1 *}$, Q. Pei ${ }^{1}$, S. M. Sapuan' ${ }^{2}$ N. Abdul Aziz ${ }^{2}$ and M. Z. Mohamed Yusoff ${ }^{2}$ \\ ${ }^{1}$ Mechanical Engineering Department, UCSI University, 1, Jalan Menara Gading, UCSI \\ Heights, 56000 Cheras, Kuala Lumpur, Malaysia. \\ *Email: suhana@ucsiuniversity.edu.my \\ Tel: +60391018880 \\ ${ }^{2}$ Department of Mechanical and Manufacturing Engineering, University Putra Malaysia, \\ Malaysia
}

\begin{abstract}
Malaysia is categorised as one of the countries with a high number of road crashes involving deaths. This indicated the necessity of improving the safety system of a vehicle including the passive system which comprises of the bumper as one of the systems. In the frontal impact, the bumper system is the first vehicle part that receives the impact. Therefore, a crashworthy bumper that can protect the occupant is essential. In this research, the crash performance of OPEFB fibre/epoxy composite bumper beam has been investigated using finite element analysis. Low-velocity impact of $4 \mathrm{~km} / \mathrm{h}$ between impact block and the bumper beam was simulated using LS-DYNA in accordance to Federal Motor Vehicle Safety Standards (FMVSS) 581 regulation. The composite was found exhibited comparable specific energy absorption with the aluminum bumper beam. Mass reduction of around 56\% was observed. The peak force required for damage initiation for the composite bumper beam reduced by about $90 \%$ with impact time lengthen by around $89 \%$. The velocity-history curves revealed a lower level of deceleration could be obtained through the utilisation of the composite bumper beam.
\end{abstract}

Keywords: Bumper beam, OPEFB fibre, crashworthiness, bio-composite.

\section{INTRODUCTION}

Three mains criteria are considered when selecting material to be adapted in automotive parts. The material should be able to offer lightweight properties, cost-effectiveness and crashworthiness. Metals used to be used extensively to make up bumper structure due to their high strength and stiffness. However, due to considerable demand for lightweight properties for automotive parts, which can contribute to lower fuel consumption, engineers began to replace metals with plastic and synthetic fibre polymer composite. At present, the polymer has been reinforced with synthetic fibres such as carbon and glass to achieve lightweight material with superior properties at lower cost. Moghaddam and Ahmadian [1] has analysed a bumper design employing glass material thermoplastic (GMT). The analysis is conducted numerically utilising short fibre composite with mechanical spring mechanism as the energy absorber and subjected to a frontal impact test according to American bumper standard. It is found that the bumper is able to absorb around $80 \%$ of the kinetic impact energy but weighed about two times lower when compared to steel. Prabhakaran, Chinnarasu and Kumar [2] analysed composite made up of E-Glass/Epoxy bidirectional laminates to substitute steel as a material for light 
passenger vehicle bumper beam. The composite was fabricated into bumper shape using hand lay-up technique for weight comparison purpose. The steel bumper weighs about $5.15 \mathrm{~kg}$ while the weight of the composite bumper is $2.38 \mathrm{~kg}$, which is around $53.8 \%$ lesser than the steel bumper. Lightweight components with high energy absorbing ability add positive values to an automobile's performance [3].

Glass-fibre-reinforced plastics have proven to meet the structural and durability demands of automobile interior and exterior parts. Good mechanical properties and a well-developed, installed manufacturing base have aided in the insertion of glass fibrereinforced plastics within the automotive industry. However, glass-reinforced plastics exhibit shortcomings such as their relatively high fibre density (approximately 40\% higher than natural fibres), difficult to machine, and poor recycling properties, and the potential health hazards posed by glass-fibre particulate [4]. Researchers are investigating the usage of natural fibre instead of the synthetic fibre as reinforcement material to overcome the drawbacks. Due to the environmental awareness and sustainability concept, the use of bio-composite material as bumper material is hence worthy of analysis. Also, bio-composite also offer cost and weight reduction. Jeyanthi et al. [5] investigated the properties of twisted long kenaf fibre reinforced polypropylene composite to be adapted for the bumper. It was found that the impact strength value for the composite was comparable to the glass fibre reinforced polypropylene composite. Ramyasree, Venkataramaniah and Kumar [6], analysed the crash performance of front bumper beam with the finite element by employing steel, Aluminium, glass mat thermoplastic (GMT), sheet moulding compound (SMC), long glass fibre reinforced thermoplastic (LFRT) and kenaf long fibre reinforced thermoplastic (KLFRT) as the material. The frontal impact was simulated following Federal Motor Vehicle Safety Standard (FMVSS) and Insurance Institute for Highway Safety (IIHS) with a velocity of impact barrier of $48 \mathrm{~km} / \mathrm{h}$ and 68 $\mathrm{km} / \mathrm{h}$, respectively. The result shows that KLFRT obtained higher deflection value as compared to other materials. The maximum displacement obtained for KLFRT was 61.2 $\mathrm{mm}$ at $6.7 \mathrm{~ms}$ as per FMVSS and $78.5 \mathrm{~mm}$ at $6.2 \mathrm{~ms}$ as per IIHS. Due to the low rigidity of LFRT and KLFRT, the impact force was shown to have a longer time interval indicating good energy absorption capacity. These researches suggest the possibility of replacing glass fibre with the natural fibre in the automotive application.

The advancement of finite element software has enabled the crashworthiness of vehicle structure to be simulated rather than merely determined through the experimental test, which is rather time-consuming and expensive. The crash analysis could be conducted by applying an impact to the bumper component. The impact is categorised into two types, which are elastic impact and inelastic impact. In an elastic impact, there will be a no loss of kinetic energy between the two impacting objects while in inelastic impact; part of the kinetic energy changed to another form of energy. On a collision course, the mass of the contactors is constant, but their velocity suffers great changes. Total energy involves during a collision will be conserved throughout the process. When a collision happened, the objects that are in contact will be exerting force to one another. The principle of conservation of momentum states that when two or more bodies interact, the total momentum is conserved (i.e. not changed), provided no external force acts on the bodies [7]. When modelling a collision between a vehicle and an impactor, the energy and momentum conservation equation after separation point can be expressed as follow [8]:

$$
\frac{1}{2} \mathrm{~m}_{\mathrm{A}} \mathrm{v}_{\mathrm{A}}^{2}=\frac{1}{2} \mathrm{~m}_{\mathrm{A}} \mathrm{v}_{\mathrm{A} 1}^{2}+\frac{1}{2} \mathrm{~m}_{\mathrm{B}} \mathrm{v}_{\mathrm{B} 1}^{2}
$$




$$
\mathrm{m}_{\mathrm{A}} \mathrm{v}_{\mathrm{A}}=\mathrm{m}_{\mathrm{A}} \mathrm{v}_{\mathrm{A} 1}+\mathrm{m}_{\mathrm{B}} \mathrm{v}_{\mathrm{B} 1}
$$

where $m_{A}$ is the mass of the impactor, $m_{B}$ the mass of the vehicle, $v_{A}$ the velocity of the impactor before impact, $\mathrm{v}_{\mathrm{A} 1}$ the final velocity of the impactor after separation point, and $\mathrm{V}_{\mathrm{B} 1}$ the final velocity of the vehicle after separation point. The plastic strain energy which is represented by the letter $\mathrm{E}$ is gained by subtracting the kinetic energy of the vehicle and the impactor after impact from the kinetic energy of the impactor before impact:

$$
\mathrm{E}_{\text {plastic }}=\frac{1}{2} \mathrm{~m}_{\mathrm{A}} \mathrm{v}^{2} \mathrm{~A}+\frac{1}{2} \mathrm{~m}_{\mathrm{B}} \mathrm{v}^{2}{ }_{\mathrm{B}}-\frac{1}{2} \mathrm{~m}_{\mathrm{A}} \mathrm{v}^{2} \mathrm{Al}^{-}-\frac{1}{2} \mathrm{~m}_{\mathrm{B}} \mathrm{v}_{\mathrm{B} 1}^{2}
$$

The amount of energy absorbed during the collision strongly determines the crashworthiness properties of a structure like a car bumper. Equation (3) indicates the ability of a structure to absorb the collision kinetic energy by plastic deformation. Higher energy-absorbing capacity in the event of crash lowers the fatalities incurred.

Bumper beam serves as an important structural component which can provide substantial energy absorption during a crash event. Conventionally, the bumper beam has been fabricated using aluminium. This study aims to evaluate the potential application of the OPEFB fibre reinforced epoxy composites as the material for car bumper. The incorporation of OPEFB fibre is expected to significantly increase the impact strength of the bumper as OPEFB fibre will play the role to absorb the impact energy in the event of a collision. In this study, the crash performance of OPEFB fibre/epoxy composite bumper beam was evaluated and compared against the conventional Aluminum bumper beam.

\section{METHODOLOGY}

Figure 1 shows the schematic of the finite element setup for crash analysis of bumper beam. A point mass represents the rear of the vehicle. The point mass was rigidly attached to the bumper to attain the gross mass of 1.2 ton in order to simulate the vehicle mass. A pendulum impact device with a low initial velocity of $4 \mathrm{~km} / \mathrm{h}$ was set in accordance to the FMVSS 581 standard with a mass of the impact device set equivalent to the mass of the vehicle. The model of bumper beam and the block impact device were adopted based on FMVSS 581. The beam and block impact device were idealized using 6124 and 27298 shell and solid elements, respectively. All contact surfaces were defined using *AUTOMATIC_SURFACE_SURFACE contact card. No constraints applied to the bumper since the restraint is maintained by the global inertia of the vehicle. For comparison purpose, a baseline model was simulated using current material employed for a bumper structure which is aluminium AA5182. 


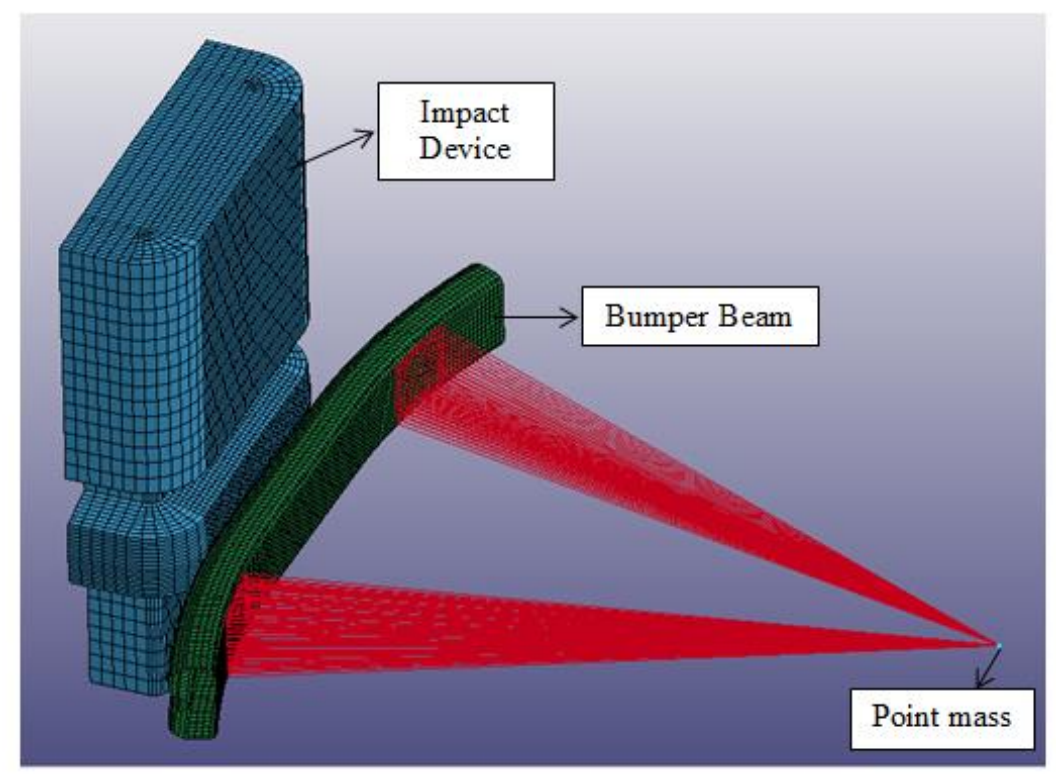

Figure 1. FEA model of a bumper beam impact system

The material properties of these materials are listed in Table 1. The aluminium bumper beam was modelled using material type 24 (MAT_PIECEWISE_LINEAR_PLASTICITY) which requires the stress and strain curve for the material to be defined. The stress-strain graph for the aluminium is shown in Figure 2. The composite bumper system was modelled with the LS-DYNA material model MAT 55 (MAT_ENHANCED_COMPOSITE_DAMAGE). The material properties of the composite used were based on Hassan et al. [9].

Table 1. Material properties of the baseline model.

\begin{tabular}{lcccc}
\hline Material & $\begin{array}{c}\text { Young's modulus, E } \\
(\mathrm{MPa})\end{array}$ & Poisson ratio, $v$ & $\begin{array}{c}\text { Yield stress } \\
(\mathrm{MPa})\end{array}$ & $\begin{array}{c}\text { Density, } \rho \\
\left(\text { ton } / \mathrm{mm}^{3}\right)\end{array}$ \\
\hline $\begin{array}{l}\text { Aluminum } \\
\text { AA5182 }\end{array}$ & 7910 & 0.3 & 134.83 & $2.75 \mathrm{e}-9$ \\
\hline
\end{tabular}

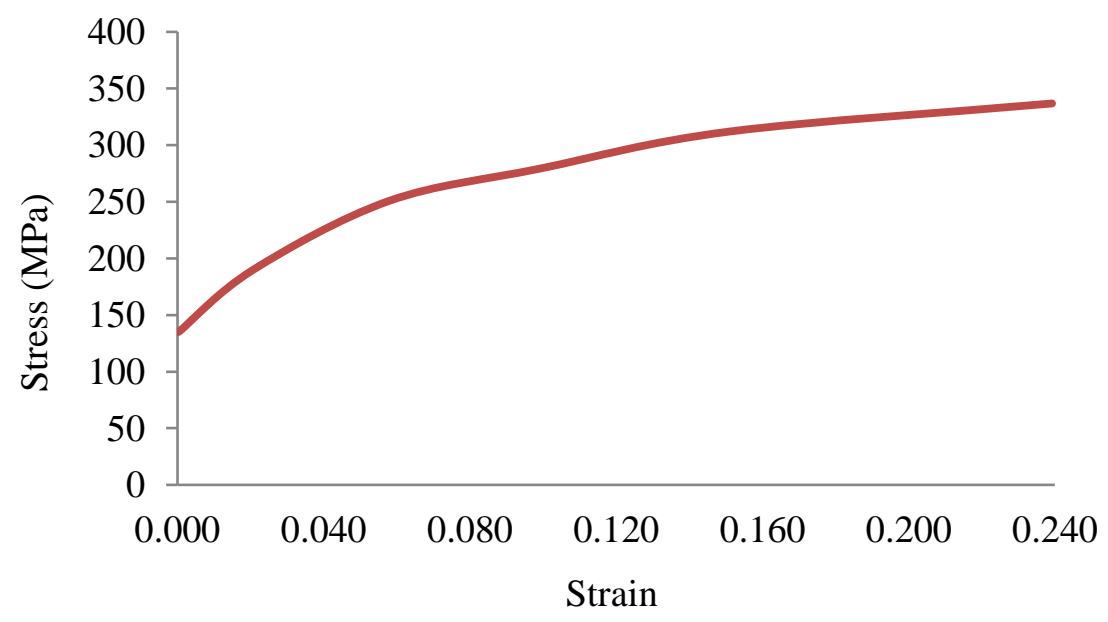

Figure 2. Stress strain relation for the baseline model material. 


\section{RESULTS AND DISCUSSION}

To verify the accuracy of the crash simulation, it is necessary to evaluate the energy balance of the simulation [10]. In finite element explicit models, if the total energy is approximately constant, the value of the total error is generally less than $1 \%[11,12]$. Figure 3(a) and (b) show the energy history plot for aluminium and $0^{\circ}$ unidirectional OPEFB fibre/epoxy composite bumper beam under low-velocity impact, respectively. It can be seen from both figures that the total energy is approximately constant, that is the crash analysis results are verified, and the kinetic energy transforms into internal energy during the simulation. The total energy for both simulations accumulates to $741 \mathrm{~J}$ that is equivalent to the initial kinetic energy imposed by the impactor.

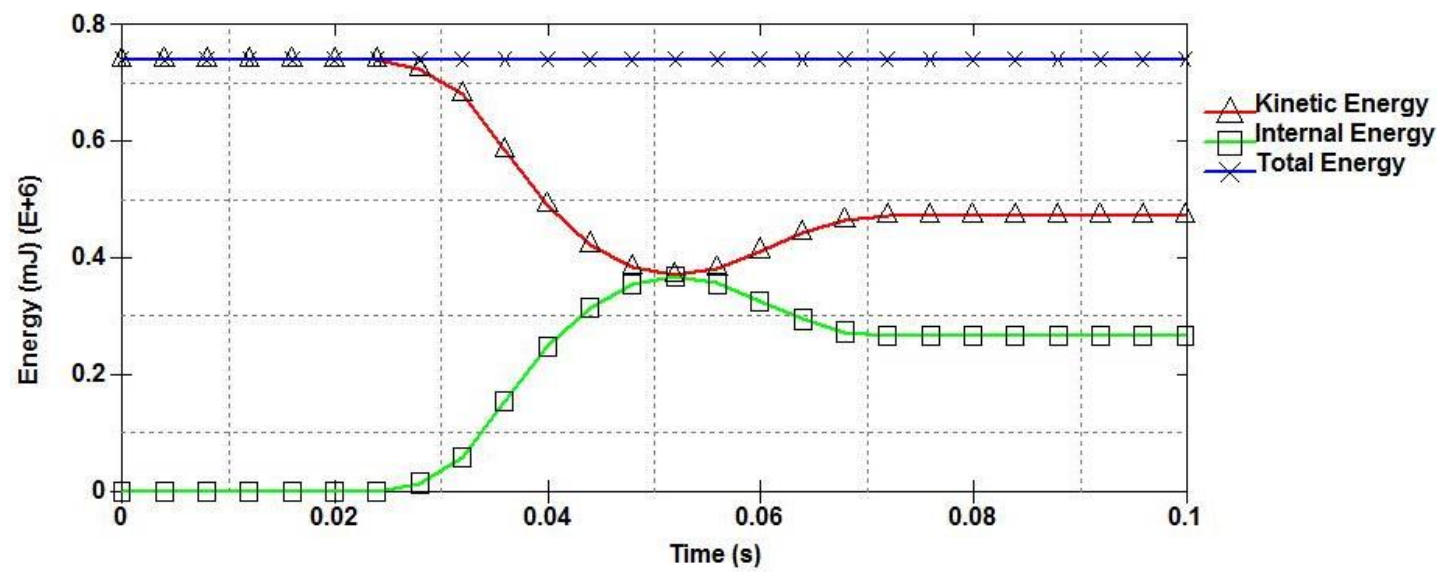

(a)

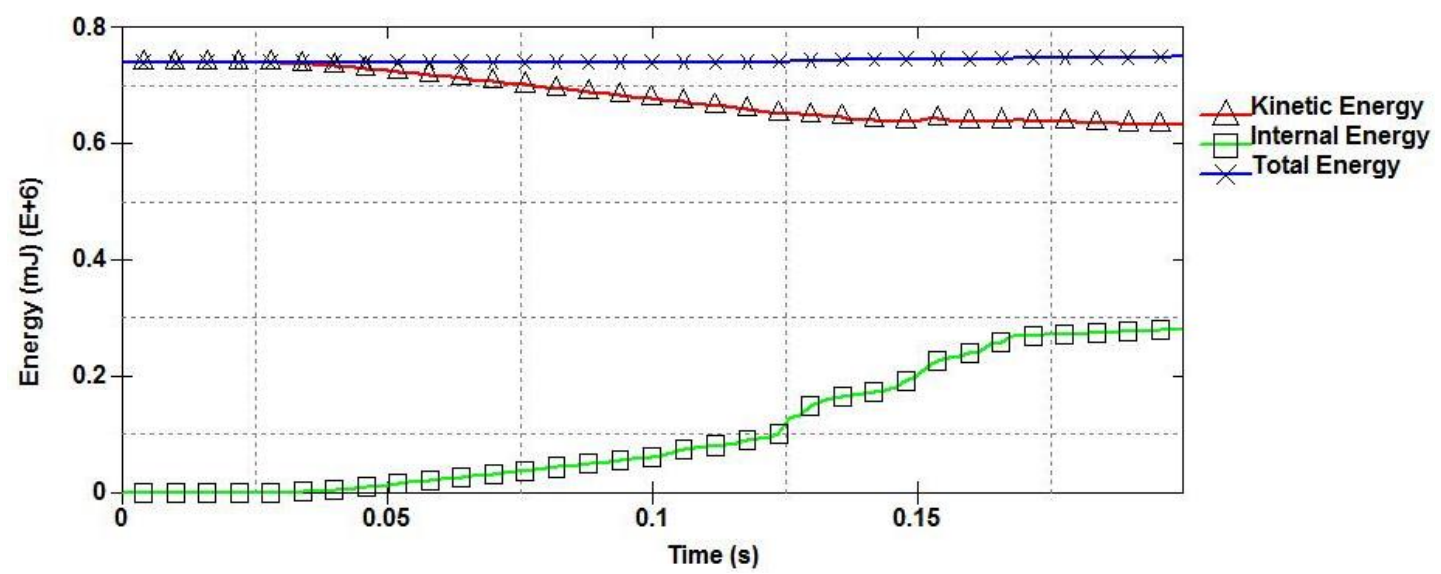

(b)

Figure 3. Energy history plot for the impact of (a) aluminium bumper beam and; (b) OPEFB fibre/epoxy composite bumper beam.

Another verification of the simulation work would be based on the hourglass energy, that is the non-physical energy components that do not generate any stress or strain and hence affecting the accuracy of the solution by interfering with the structure's true response. According to the ECE R66 standard, the maximum permissible amount of the hourglass energy is 5\% of the total energy [12-14]. If the hourglass energy is lesser than $5 \%$ of the total energy, the simulation result is reliable [15]. Figure 4(a) and (b) 
shows the hourglass energy plot for the impact of aluminium and the composite bumper beam, respectively. The maximum hourglass energy for the aluminium bumper beam is $0.197 \mathrm{~J}$ which is only about $0.03 \%$ of the total energy. The maximum hourglass energy for the composite bumper beam, on the other hand, is $0.629 \mathrm{~J}$, which is around $0.08 \%$ of the total energy. With value lesser than $5 \%$, the hourglass energy of the two impact models has no significant impact on the simulation results which therefore can be considered as authentic.

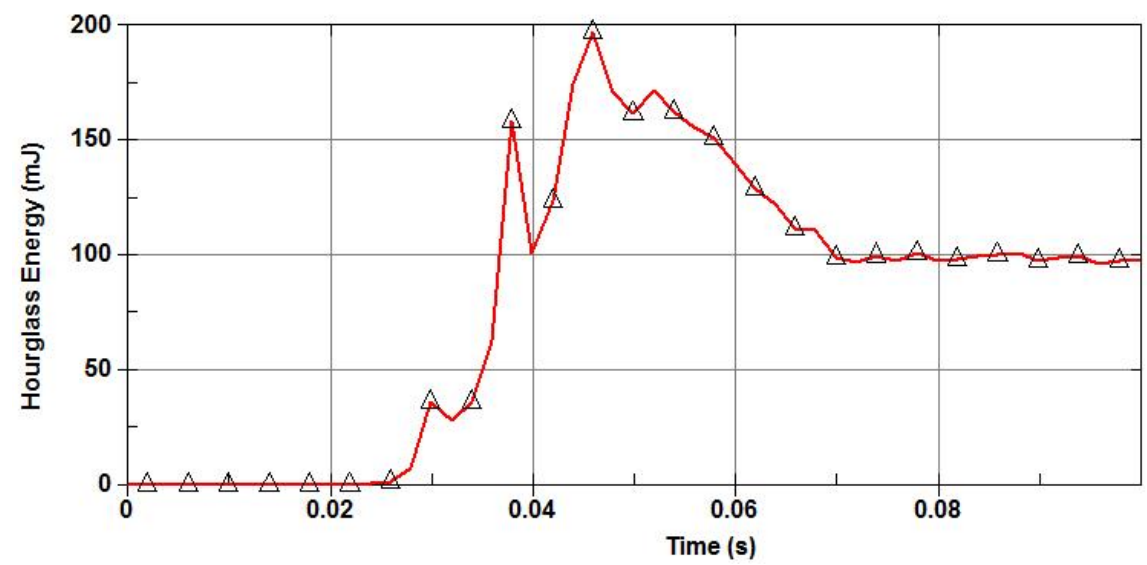

(a)

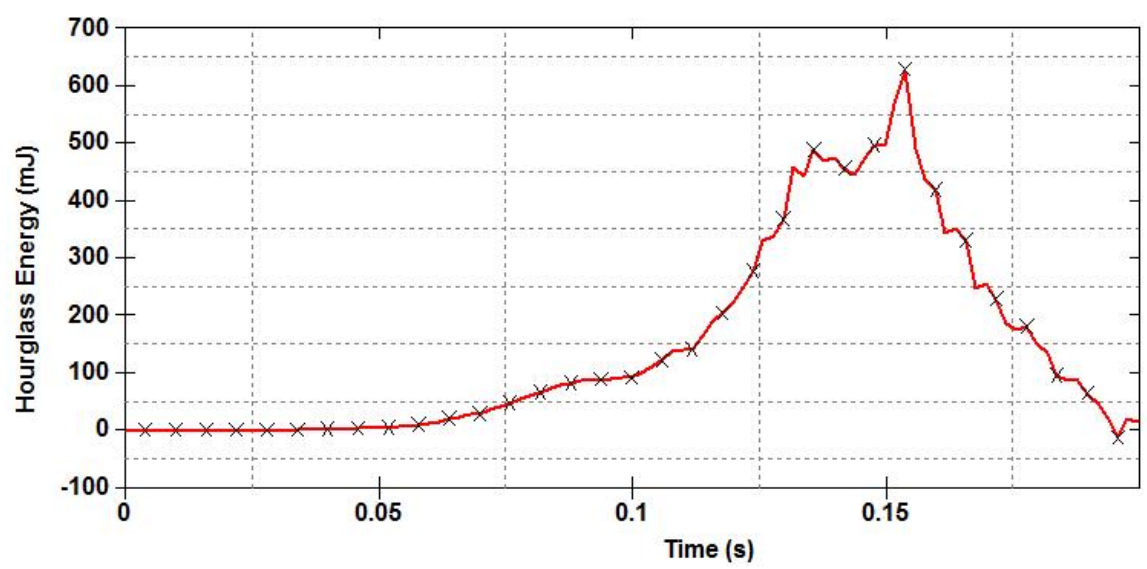

(b)

Figure 4. Hourglass energy history plot for the impact of (a) aluminium bumper beam and; (b) OPEFB fibre/epoxy composite bumper beam.

The simulation results, as shown in Figure 4(a) and (b) earlier indicate that the aluminium bumper beam gets maximum deformation at about $0.052 \mathrm{~s}$ with the value of $32.36 \mathrm{~mm}$ while the OPEFB fibre/epoxy composite bumper beam at about $0.17 \mathrm{~s}$ with the value of $163.2 \mathrm{~mm}$. The contour map of deformation for aluminium and the OPEFB fibre/epoxy composite bumper beam is shown in Figure 5(a) and (b) respectively. Substantial deformation is observed for the composite bumper as compared to the aluminium bumper beam. 


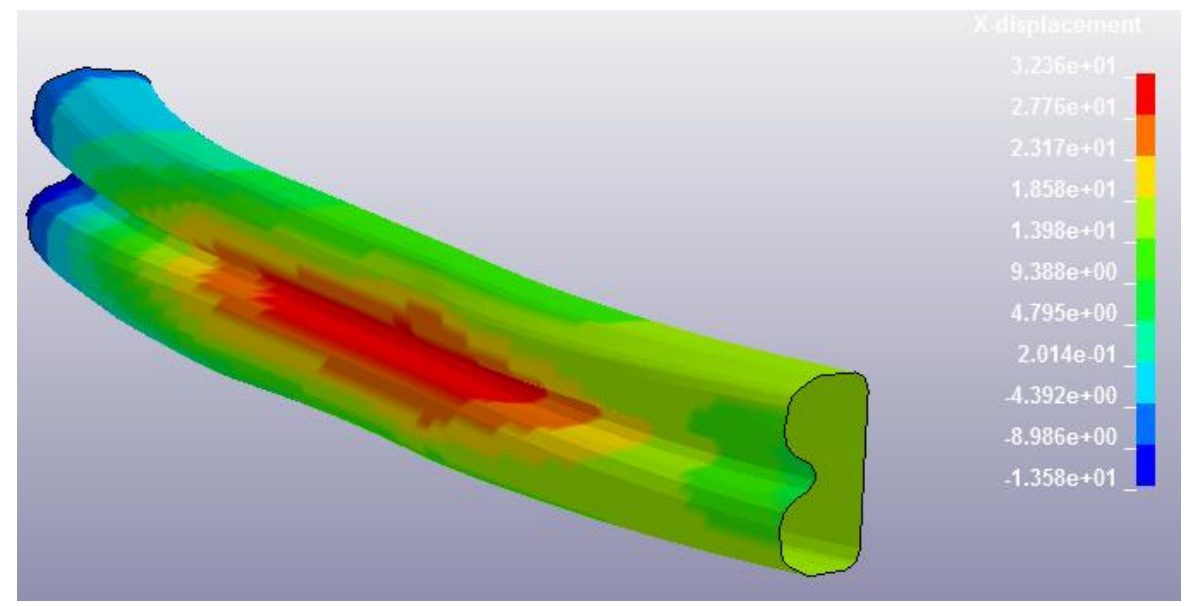

(a)

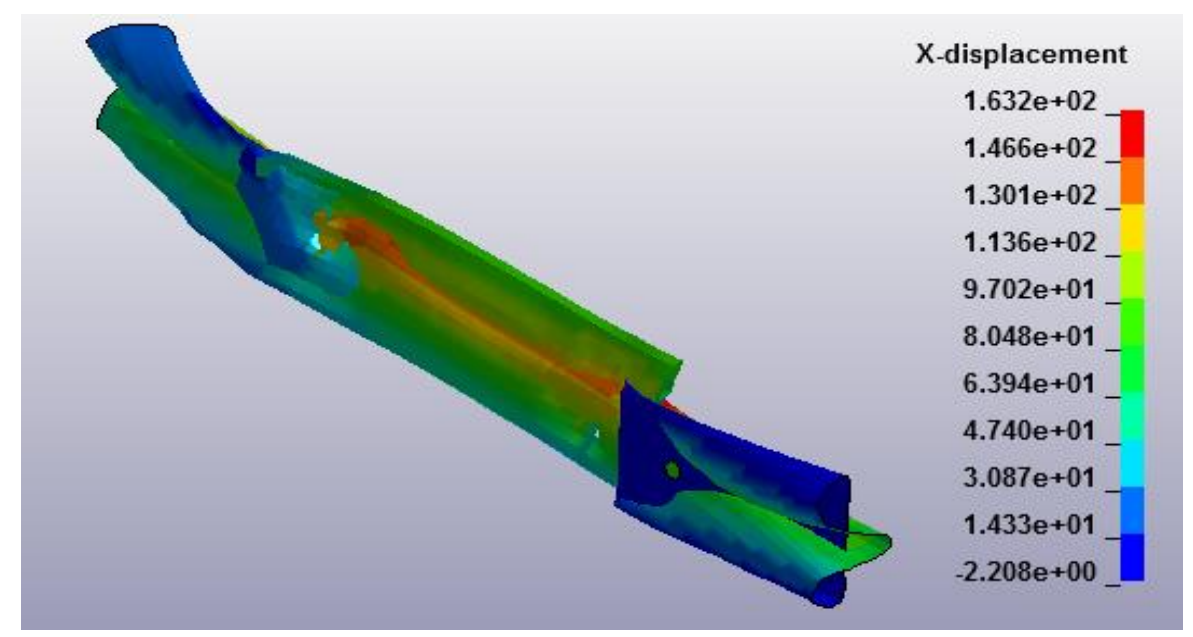

(b)

Figure 5. Deformation of (a) aluminium bumper beam and (b) OPEFB fibre/epoxy composite bumper beam under low-velocity frontal impact

Force versus time curves for the crash analysis is shown in Figure 6. Aluminium bumper beam requires a high peak force to initiate damage which will eventually cause a high level of deceleration on passengers. The damage on the composite bumper beam, on the other hand, initiates at low force value with prolonged contact time as compared to the aluminium bumper beam. Composite bumper beam reveals good performance by dispersing the force deployment and extend contact force period which helps reduce sudden large damage. Similar finding observed by Kashinath and Balasaheb [16] in their evaluation on the effectiveness of glass fibre composite as material for the bumper beam. The contact time for the composite bumper beam almost twice of the aluminium bumper beam. The contact force between the impactor and aluminium bumper system reaches its peak at about $0.048 \mathrm{~s}$ with a value of $32.2 \mathrm{kN}$ and changes to 0 at about $0.074 \mathrm{~s}$ when the impact is terminated. The OPEFB fibre/epoxy composite bumper beam on the other hand experiences the maximum contact force of $4.17 \mathrm{kN}$, less by around $87 \%$ of the aluminium bumper beam, at about $0.11 \mathrm{~s}$. The impact is then terminated at about $0.18 \mathrm{~s}$. 


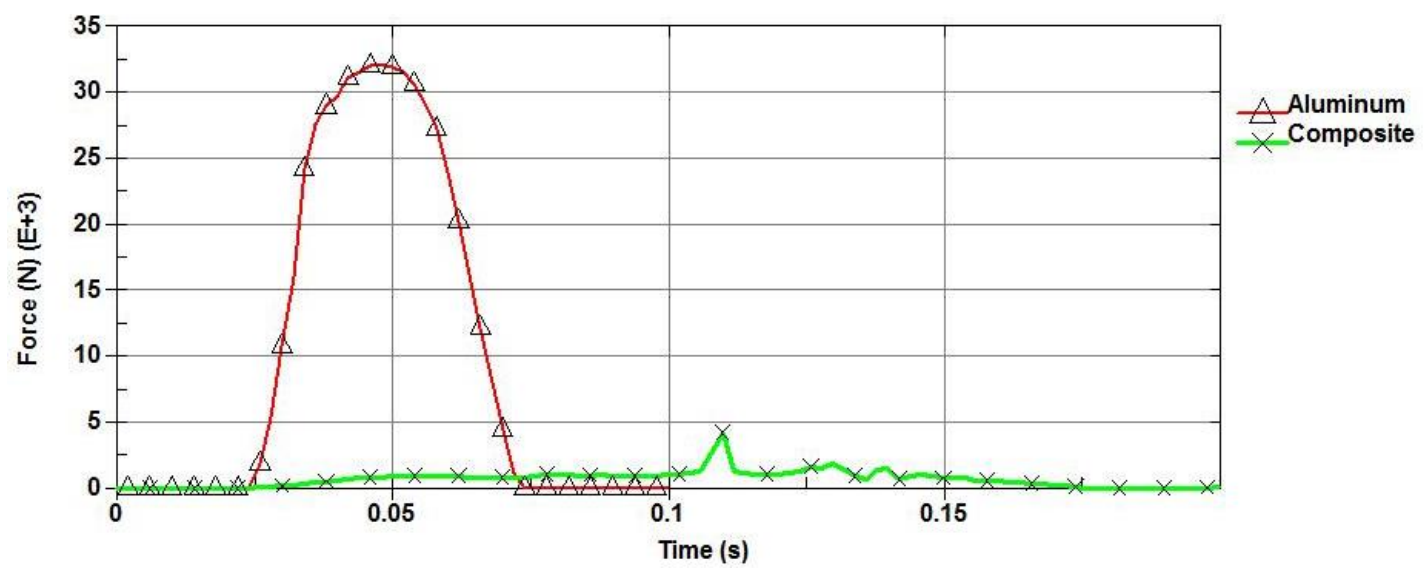

Figure 6. Comparison of the force/time characteristics between aluminium and composite bumper beam

Figure 7 shows the comparison of the internal energy-time plot between the aluminium and OPEFB fibre/epoxy composite bumper beam. The aluminium bumper beam absorbed and terminated with a higher amount of internal energy as compared to the composite bumper beam. This is an indication that the aluminium permanent plastic deformation is relatively small compared to the composite bumper beam. The specific energy absorption (SEA) for both materials is shown in Table 2. It is observed that the SEA of the composite bumper beam improved by around $52 \%$ as compared to the Aluminium bumper beam with a reduction of mass around $56 \%$.

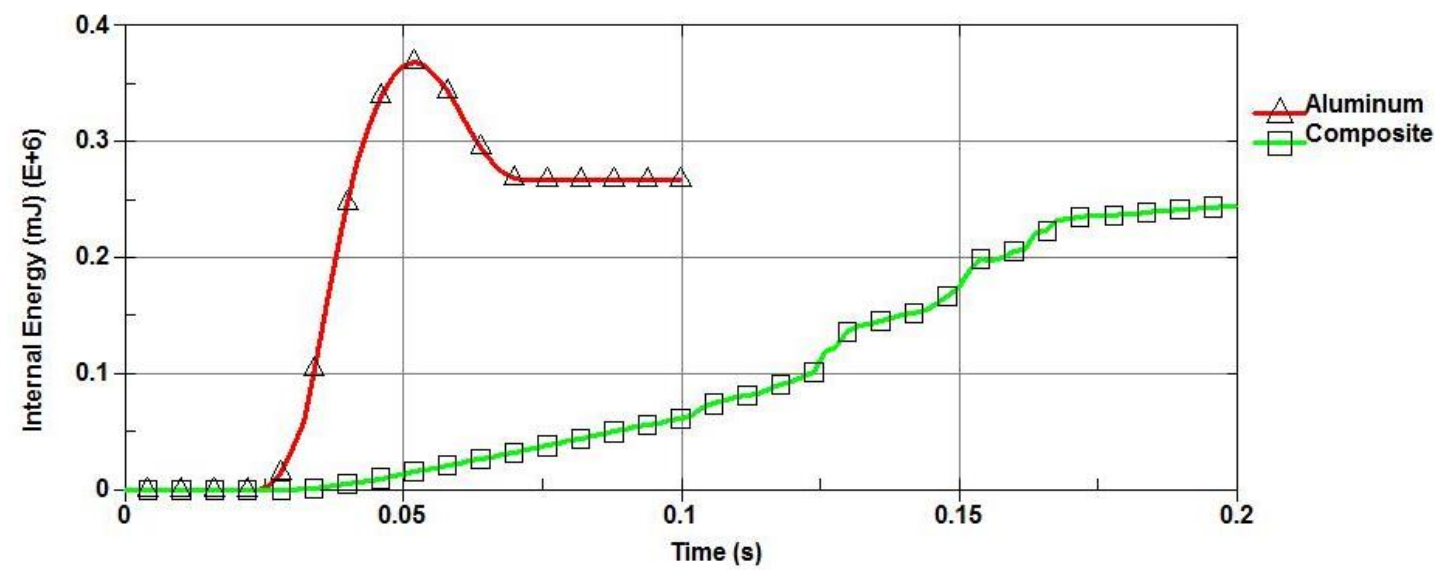

Figure 7. Comparison of the internal energy/time characteristics in aluminium with the composite bumper beam.

Table 2. Specific energy absorption capabilities for a bumper beam of different materials

\begin{tabular}{lccc}
\hline Material & Mass (kg) & $\begin{array}{c}\text { Maximum internal energy } \\
\text { absorption }(\mathrm{J})\end{array}$ & $\begin{array}{c}\text { Specific energy } \\
\text { absorption }(\mathrm{J} / \mathrm{kg})\end{array}$ \\
\hline Aluminium & 2.87 & 369 & 128.57 \\
Composite & 1.25 & 245 & 196 \\
\hline
\end{tabular}


The crush force efficiency (CFE) was measured based on the ratio of average force to the maximum force, where the former one is calculated by dividing the energy absorbed with the displacement. Table 3 shows the CFE for both applied bumper beam material model. It is observed that the CFE of the composite bumper beam is comparable to the $\mathrm{CFE}$ of the conventional aluminium bumper beam.

Table 3. Crush force efficiency of the bumper beam.

\begin{tabular}{cccccc}
\hline Material & $\begin{array}{c}\text { Energy } \\
\text { absorbed }(\mathrm{J})\end{array}$ & $\begin{array}{c}\text { Displacement } \\
(\mathrm{mm})\end{array}$ & $\begin{array}{c}\text { Average } \\
\text { force }(\mathrm{kN})\end{array}$ & $\begin{array}{c}\text { Peak force } \\
(\mathrm{kN})\end{array}$ & CFE \\
\hline Aluminum & 369 & 32.36 & 11.4 & 32.2 & 0.35 \\
Composite & 245 & 163.2 & 1.50 & 4.17 & 0.36 \\
\hline
\end{tabular}

Figure 8 shows the time history of the velocities incurred by the impactor throughout the collision process. The slope of the velocity plot shows the intensity and timing of the collision. The impactor comes to rest faster when colliding with the aluminium bumper beam. These plots are an indication of the higher level of deceleration when a collision happens with aluminium bumper beam in comparison with the longer deceleration time and low level of deceleration when a collision happens with the composite bumper beam. The maximum deceleration suffered by the impactor during the collision is summarised in Figure 9. The deceleration suffered by the impactor reduced by around $89 \%$.

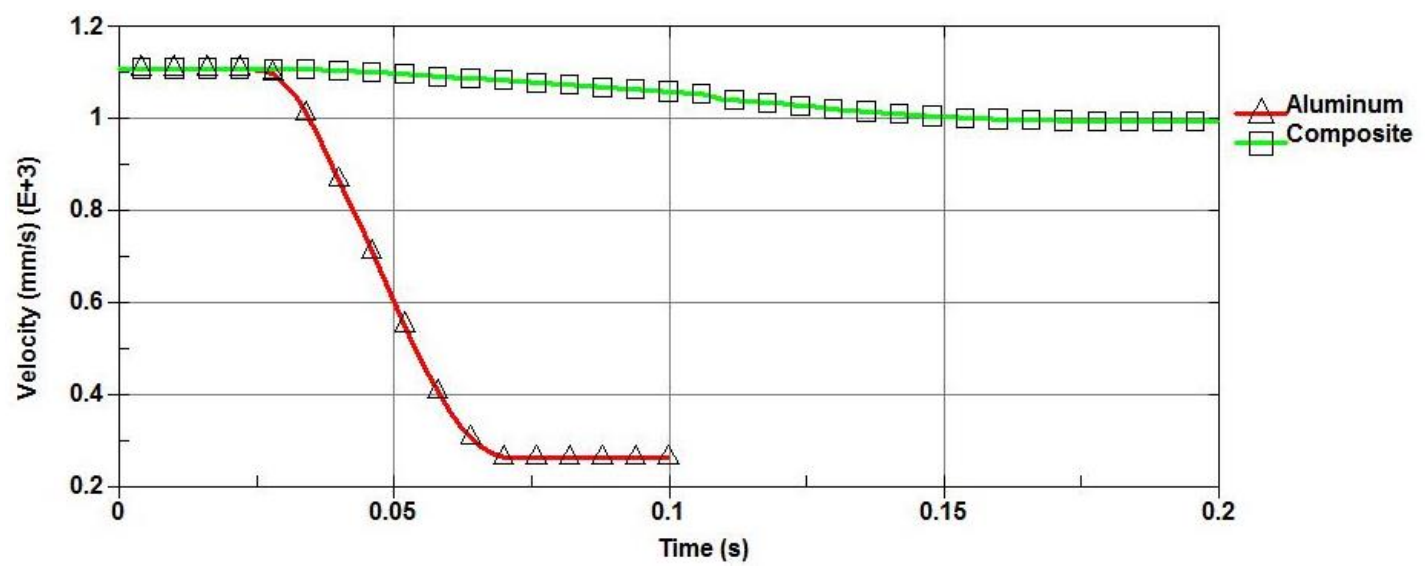

Figure 8. Comparison of the velocity/time characteristics in aluminium with the composite bumper beam. 


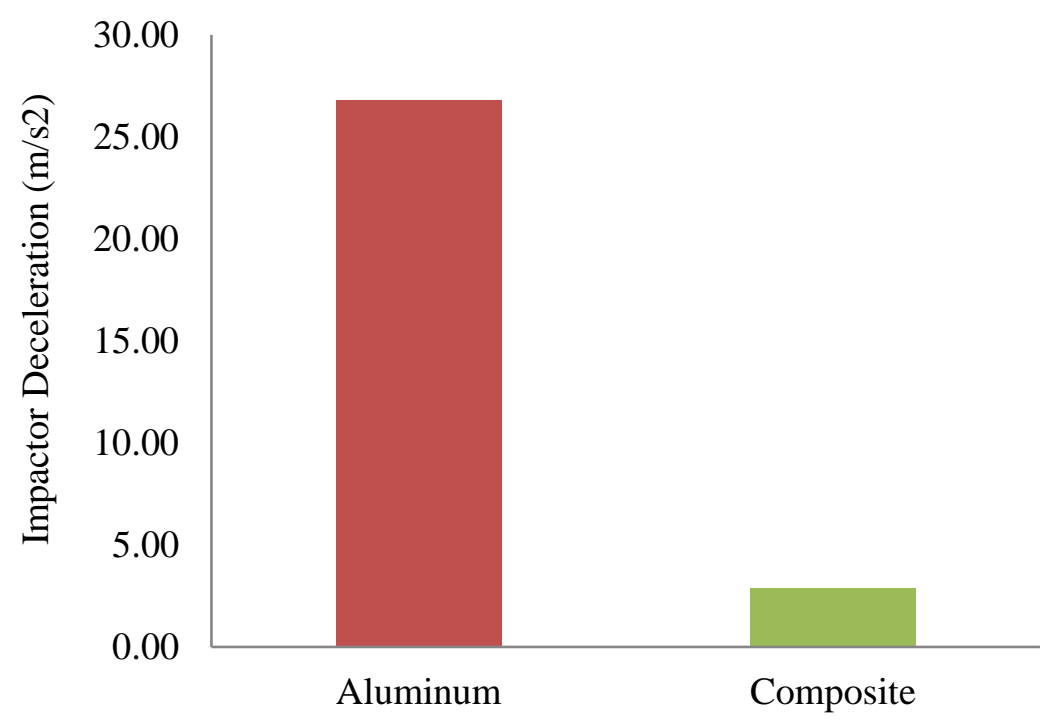

Figure 9. Deceleration of impactor during bumper beam collision.

\section{CONCLUSION}

Finite element analysis was conducted to compare the crash performance of unidirectional OPEFB fibre/epoxy composite bumper beam with the conventional aluminium bumper beam, under low-velocity impact. To compare the crash performance of the system, the measure of specific energy absorption, peak force upon impact and velocity diagram were computed. Deformation of both bumper beams was observed and analysed. Severe deformation was observed in the composite bumper beam compared to the aluminium bumper beam. The specific energy absorption of the composite bumper beam was found to be comparable to the aluminium bumper beam with an added advantage of mass reduction of around $56 \%$. The peak force required for damage initiation for the composite bumper beam reduced approximately $90 \%$ with impact time lengthen of $89 \%$. The velocity-history curves revealed a lower level of deceleration could be obtained through the utilisation of the composite bumper beam. The results demonstrated the applicability of the composite to replace the aluminium for bumper beam application. The higher plastic deformation of the composite contributed to the ability of the composite material to absorb the impact energy from the collision thereby minimising the impact to the passenger.

\section{REFERENCES}

[1] Moghaddam a RM, Ahmadian MT. Design and Analysis of an Automobile Bumper with the Capacity of Energy Release Using GMT Materials. Engineering and Technology 2011; 5: 837-844.

[2] Prabhakaran S, Chinnarasu K, Kumar MS. Design and Fabrication of Composite Bumper for Light Passenger Vehicles. International Journal of Modern Engineering Research 2012; 2: 2552-2556.

[3] Salwani MS, Sahari BB, Ali A, et al. The Effect of Automotive Side Member Filling on Car Frontal Impact Performance. Journal of Mechanical Engineering and Sciences 2014; 6: 873-880.

[4] Holbery J, Houston D. Natural-fiber-reinforced polymer composites in automotive 
applications. The Journal of The Minerals, Metals \& Materials Society 2006; 58: 80-86.

[5] Jeyanthi S, Paul ChandraKumar J, Rajesh Kumar N, et al. An investigation on dynamic mechanical analysis and low velocity impact analysis of natural thermoplastic composite frontal beams. International Journal of Applied Engineering Research 2014; 9: 13709-13718.

[6] Ramyasree L, Venkataramaniah D, Kumar GN. Impact Analysis of Frontal Car Bumper using Long Fibre Reinforced Thermoplastics. International Journal of Current Engineering and Technology 2015; 55: 2277-4106.

[7] Breithaupt J. Physics. Palgrave Macmillan, 2015.

[8] Marzbanrad J, Alijanpour M, Kiasat MS. Design and analysis of an automotive bumper beam in low-speed frontal crashes. Thin-Walled Structures 2009; 47: 902911.

[9] Hassan CS, Yeo CW, Sahari B, et al. Mechanical properties of unidirectional oil palm empty fruit bunch (OPEFB) fiber reinforced epoxy composite. IOP Conference Series: Materials Science and Engineering; 206. Epub ahead of print 2017.

[10] Baykasoglu C, Mugan A, Sunbuloglu E, et al. Rollover crashworthiness analysis of a railroad passenger car. International Journal of Crashworthiness 2013; 18 : 492-501.

[11] Kang KT, Chun HJ, Park JC, et al. Design of a composite roll bar for the improvement of bus rollover crashworthiness. Composites Part B: Engineering 2012; 43: 1705-1713.

[12] Partovi Meran A, Toprak T, Muğan A. Numerical and experimental study of crashworthiness parameters of honeycomb structures. Thin-Walled Structures 2014; 78: 87-94.

[13] Riazi S, Feizi MM, Hosseini-Tehrani P. Improving crashworthiness in railcar against rollover. Transactions of the Canadian Society for Mechanical Engineering 2012; 36: 383-397.

[14] United Nations. Uniform technical prescriptions concerning the approval of large passenger vehicles with regard to the strength of their superstructure: Regulation No. 66. Revision 1.

[15] Wang T, Li Y. Design and analysis of automotive carbon fiber composite bumper beam based on finite element analysis. Advances in Mechanical Engineering 2015; 7: $1-12$.

[16] Kashinath KS, Balasaheb CA. Review of Design \& Analysis of Bumper Beam in Low Speed Frontal Crashes. International Journal of Industrial Electronics and Electrical Engineering 2014; 27-34. 